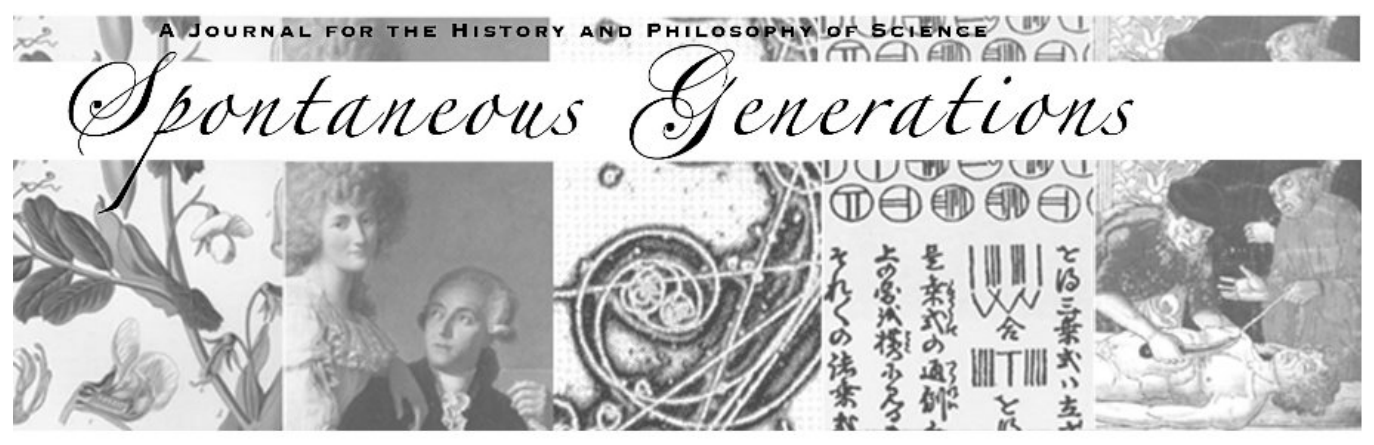

\title{
Conceptual Sea Changes
}

Author(s): Paul Humphreys

Source: Spontaneous Generations: A Journal for the History and Philosophy of Science, Vol. 4, No. 1 (2010) 111-115.

Published by: The University of Toronto

DOI: $10.4245 /$ sponge.v4i1.14185

EDITORIAL OFFICES

Institute for the History and Philosophy of Science and Technology Room 316 Victoria College, 91 Charles Street West

Toronto, Ontario, Canada M5S 1K7

hapsat.society@utoronto.ca

Published online at jps.library.utoronto.ca/index.php/SpontaneousGenerations ISSN 19130465

Founded in 2006, Spontaneous Generations is an online academic journal published by graduate students at the Institute for the History and Philosophy of Science and Technology, University of Toronto. There is no subscription or membership fee. Spontaneous Generations provides immediate open access to its content on the principle that making research freely available to the public supports a greater global exchange of knowledge. 


\title{
Conceptual Sea Changes*
}

\author{
Paul Humphreys ${ }^{\dagger}$
}

\begin{abstract}
The reshaping of much scientific research around computational methods is not just a technological curiosity. It results in a significant reshaping of conceptual and representational resources within science in ways with which many traditional philosophical positions are ill-equipped to cope. Some illustrations of this are provided and a consequence for the roles of science and the arts is noted.
\end{abstract}

One of the ironies of academic life is the persistent view that creative work is largely confined to literature and the fine arts. Kuhn's interdisciplinary hit, The Structure of Scientific Revolutions, reinforced this prejudice, but despite the promise of its title, it presents the overwhelming bulk of work in normal science as profoundly conservative, a feature noted by Anouk Barberousse and Cyrille Imbert (2010). Perhaps this explains why professors of English hold the book in such high regard. There is little doubt that different personality types are drawn to science and the arts, yet if one looks moderately carefully at the historical development of the two domains, the conventional view that science is largely pursued by dullards and that the representational arts swarm with dashing innovators is seriously wrong.

One reason for the adventurous spirit prevalent in much scientific research is the fact that the world forces us to expand our conceptual resources beyond those that are innate or are learned through exposure to everyday life. In order to effectively deal with aspects of the world that lie beyond our biologically evolved conceptual frameworks, new representations are needed whether we pursue prediction, truth-seeking activities, engineering, or many of the other activities loosely associated with science. In contrast, literature is largely constrained by the need to remain in contact with specifically human concerns, with the possible exception of science fiction which all too often remains attached to anthropomorphic forms of life. The arts, almost without exception, are tethered to the human senses, whether visual, acoustic, tactile, olfactory,

* Received 14 July 2010.

$\dagger$ Paul Humphreys is Professor of Philosophy at the University of Virginia. His current research interests include computational science, emergence and general philosophy of science. 
or gustatory. In saying this, I do not deny that artists have invented ingenious modes of representation. But a painter or a composer who used media that humans could not hear or see (and by this I do not mean periods of silence or a blank canvas) would have only a limited career as a composer of canine music or ultra-violet paintings for bees. ${ }^{1}$

These pressures for conceptual change have often, although not exclusively, come from the use of scientific instruments. To be a scientific realist is to reject an anthropocentric position on what exists. In particular, it is to recognize that the human senses are simply five detectors with limited domains of application. The empiricism/realism controversy would not have been an issue for the philosophy of science, but would have remained as a metaphysical dispute, had it not been for the invention of, first the microscope, and then shortly thereafter, the telescope. Even these first instruments presented phenomena, such as micro-organisms, that could not be effectively or accurately described using only the concepts of then-current scientific theories.

Many items usually thought of as experimental apparatuses use instruments for detection and representation. For example, although it is usually, and appropriately, known as "the two slit experiment," the apparatus used involves an instrument for detecting interference patterns produced by diffraction and it was the patterns produced by that instrument which forced theoreticians to come to terms with some distinctively quantum mechanical concepts. Nor are fancy instruments required for us to see the need for novel concepts. Statistics is full of novel but graspable concepts such as heteroscedasticity (the variance of a sequence of random variables changes over time) and autoregression. There are loose informal analogs of these measures, but the precise definitions conceptually outrun their informal cousins and are necessary for an adequate representation of many stochastic processes. Sometimes the conceptual breakthrough comes from the development of a new form of argument: witness the spectacular refinement of our understanding of forms of infinity after Cantor's invention of the diagonalization argument and the subsequent development of systematic theories of infinity within set theory.

In Extending Ourselves (Humphreys 2004), I suggested that the next era of science will have to address the challenges posed by using these instruments, including computational instruments, to allow humans to grasp radically different ways of representing the world. Traditional empiricist, Wittgensteinian, and neo-Kantian positions are impediments to this enterprise; instead of focusing on the limits of our perceptual and

${ }^{1}$ On the latter, see Chittka and Walker (2005). 
representational abilities, we need to explore ways of enhancing them. It helps that the second two of those philosophical positions shifted the constraining frameworks from the psychological to the linguistic or the theoretical, but those constraints are neither permanent nor impermeable. Much has been made of the emergence of language as a source of human superiority and cultural evolution. Yet natural languages, as opposed to artificial representational systems, have become a hindrance, not an advantage. Now that the high water mark of linguistic determinism is behind us-although there is a continuing division of positions on the extent to which the Sapir-Whorf hypothesis is correct, there is plenty of evidence that its domain of validity is at best small-ways forward from methods of conceptual analysis grounded in familiar concepts and based on a priori methods need to be developed. ${ }^{2}$

How best, then, to expand the barriers posed by current human conceptual frameworks? There are two options: expanding human frameworks and off-loading some or most of the representational work to artificial cognizers. In both cases, it is helpful to stop thinking in terms of the usual linguistic frameworks and to think of the issues in terms of alternatives. In the case of expanding human frameworks, there is evidence that the plasticity of the human brain can result in a shifting of psychological capacities. Neural net models of cognitive capacities make this plausible, especially if one is convinced by arguments that sub-conceptual representations play a role in cognitive processing. The existence of this plasticity means that the human conceptual and "biological" frameworks are not fixed. ${ }^{3}$ We also have evidence of this adaptability from haptic technology that allows tactile sensing of properties that are not inherently touchable, such as the transformation of visual information into tactile information and, in a virtual reality setting, the ability to "touch" molecular orbitals.

What is needed is to develop an objective-not a third person!-conceptual framework to capture the contents of these newly accessible domains. Consider how thoroughly infused with anthropocentric perspectives are most philosophical discussions of related topics. Thomas Nagel's famous argument for the inadequacy of linguistic and other scientific approaches to capture what it is like to be an experiencing agent makes a persuasive case for considering the role of human and other qualia in a complete account of cognition,

2 On neo-Whorfian positions, see January and Kako (2001) and Fuhrman and Boroditsky (2010).

3 The existence of cultural universals is not at odds with this potential to reshape concepts because those universals were all developed in natural environments. 
but until there is evidence that scientific instruments and computational devices have qualia-like contents, what it is like to be a supercomputer simulating the formation of planetary systems will require a new objective conceptual apparatus specifying from the internal perspective of the computer how the formation is to be represented. Quine's pervasively influential arguments against reductive empiricism in his "Two Dogmas of Empiricism" used statements of sensory experience as forming the outer boundary of the epistemological web. ${ }^{4}$ With outputs from instruments replacing many of these observation statements as more reliable sources of knowledge, perhaps taken as direct, non-conceptual content, perhaps reformulated in a new mathematical or computational vocabulary, revision of the web's interior to preserve the boundary takes on a distinctively different cast. Related arguments that cast doubt on the a priori/a posteriori division also assume, as do most discussions of the a priori itself, that independence from experience means independence from human experience. ${ }^{5}$ Discussions of computational mathematics have redressed this problem to a limited extent, but much more needs to be done. We long ago conceded that human pattern recognition abilities are sufficiently fallible that the results of descriptive statistics and objective tests for randomness, however counter-intuitive, should prevail and there is already a considerable literature on sub-conceptual representations that can usefully be brought to bear on these issues. ${ }^{6}$

One of the main priorities is to think about problems and solution methods in terms of conceptualizing them from the machine's perspective rather than from the human perspective. The traditional roles of theories have been prediction (which subsumes solvability), explanation, understanding, and representation. Once one thinks from a machine point of view, understanding seems to be inapplicable and the elements of explanation that remain after the role of providing understanding has been removed seem to convert to pragmatic virtues rather than epistemic. For example, providing a unifying representational framework may provide some gains in efficiency of information storage and prediction, although it cannot be an overriding desideratum. ${ }^{7}$ I leave it as an exercise for the reader as to which of the causal, pragmatic, and inferential-nomological accounts of explanation make sense from a machine perspective.

4 I am not hereby endorsing Quine's arguments, which are less than fully persuasive.

${ }^{5}$ For recent discussions of the a priori, see Boghossian and Peacocke (2000).

${ }^{6}$ For a survey, see Gärdenfors (1997).

7 For reasons why theoretical unification can be counter-productive see Humphreys (1993). 
PAUL HUMPHREYS

Corcoran Department of Philosophy

University of Virginia

Charlottesville Virginia 22904-4780, USA

pwh2a@virginia.edu

\section{REFERENCES}

Barberousse, Anouk and Cyrille Imbert. 2010. Le tournant computationnel et l'innovation théorique (forthcoming).

Boghossian, Paul and Christopher Peacocke. 2000. New Essays on the A Priori. Oxford: The Clarendon Press.

Chittka, L. and J. Walker. 2005. Do bees like van Gogh's Sunflowers? Optics and Laser Technology 38: 323-28.

Froese, Tom and Adam Spiers. 2007. Toward a Phenomenological Pragmatics of Enactive Perception. University of Sussex Cognitive Science Research Papers, 593.

Fuhrman, Orly and Lera Boroditsky. 2010. Cross-Cultural Differences in Mental Representations of Time: Evidence From an Implicit Nonlinguistic Task. Cognitive Science (to appear).

Peter Gärdenfors. 1997. Symbolic, conceptual and subconceptual representations. In Human and Machine Perception: Information Fusion, eds. V. Cantoni, V. di Gesù, A. Setti and D. Tegolo, 255-70. New York: Plenum Press.

Humphreys, Paul. 2004. Extending Ourselves. New York: Oxford University Press. Humphreys, Paul. 1993. Greater Unification Equals Greater Understanding? Analysis 53: 183-88.

January, David and Edward Kako. 2001. Re-evaluating evidence for linguistic relativity: Reply to Boroditsky. Cognition 104: 417-26. 